\title{
ANALISA METODE DATA MINING PADA PRODUKSI PERIKANAN LAUT YANG DIJUAL DI TEMPAT PERIKANAN IKAN (TPI)
}

\author{
Hanifah Urbach Sari ${ }^{1}$, Agus Perdana Windarto ${ }^{2}$, Dedy Hartama ${ }^{3}$ \\ ${ }^{1,2,3}$ Program Studi Sistem Informasi STIKOM Tunas Bangsa Pematangsiantar \\ Email: ${ }^{1}$ hanifaurbachsari@gmail.com, ${ }^{2}$ agus.perdana@tunasbangsa.ac.id
}

\begin{abstract}
Abstrak
Tujuan dari penelitian agar hasil pemanfaatan sumber daya ikan dalam memproduksi perikanan laut oleh nelayan bisa baik dengan menggunakan metode clustring K-Means. Data diperoleh dari Badan Pusat Statistik (BPS) dan dibantu dengan menggunakan software Rapid Miner. Data yang digunakan dari tahun 2013-2017 yang terdiri dari 21 Provinsi. Dengan data tersebut dapat diperoleh data dengan cluster tingkat tinggi (C1) yaitu Jawa Tengah dengan produksi 587002,8 dan cluster tingkat rendah (C2) provinsi Aceh, Sumatera Utara, Sumatera Barat, Bengkulu, Lampung, Kepulauan Bangka Belitung, DKI Jakarta, Jawa Barat, DI Yogyakarta, Jawa Timur, Banten, Bali, Nusa Tenggara Barat, Kalimantan Barat, Kalimantan Tengah, Sulawesi Utara, Sulawesi Tengah, Sulawesi Selatan, Sulawesi Tenggara dan Gorontalo dengan produksi 20302,28. Hal ini dapat menjadi masukan pada pemerintah untuk provinsi yang memiliki daerah resapan air rendah menjadi perhatian lebih berdasarkan cluster yang telah dilakukan.
\end{abstract}

Kata Kunci: K-Means, Produksi Ikan Laut, Clustering, Wilayah

\begin{abstract}
The purpose of this research is that the results of the utilization of fish resources in producing marine fisheries by fishermen can be good using the K-Means clustring method. Data was obtained from the Central Statistics Agency (BPS) and assisted using RapidMiner software. Data used from 2013-2017 consisted of 21 Provinces. With these data can be obtained data with high-level clusters (C1), namely Central Java with production 587002.8 and low-level clusters (C2) provinces of Aceh, North Sumatra, West Sumatra, Bengkulu, Lampung, Bangka Belitung Islands, DKI Jakarta, West Java, DI Yogyakarta, East Java, Banten, Bali, West Nusa Tenggara, West Kalimantan, Central Kalimantan, North Sulawesi, Central Sulawesi, South Sulawesi, Southeast Sulawesi and Gorontalo with a production of 20302.28. This can be input to the government for provinces that have low water catchment areas to be of more concern based on the cluster that has been done.
\end{abstract}

Keywords: K-Means, Sea Fish Production, Clustering, Territory

\section{PENDAHULUAN}

Tempat Pelelangan Ikan (TPI) merupakan salah satu fungsi utama dalam kegiatan perikanan dan merupakan salah satu faktor yang menggerakan dan meningkatan usaha dan kesejahteraan nelayan. Keberadaan Tempat Pelelangan Ikan dengan segala aktivitasnya memberikan banyak pengaruh bagi pelaku usaha dan kelembagaan pengelola TPI. Hubungan nelayan penangkap dengan pengumpul dan bakulan serta pengelola TPI cukup berjalan baik, namun yang menjadi permasalahan adanya indikasi-indikasi bahwa mekanisme yang terjadi adalah nelayannelayan penangkap menjual hasil tangkap-tangkapannya di TPI karena sudah terikat (ijon) dengan pengumpul atau tengkulak sehingga sistem atau mekanisme pelelangan belum[1].

Adapun penelitian terlebih dahulu, setidaknya terdapat 14,58 juta atau sekitar $90 \%$ dari 16,2 juta nelayan Indonesia hidup di bawah garis kemiskinan. Ini terutama karena belum profesionalnya pengelolaan kelautan, selain belum berubahnya pola pikir nelayan. Menjadi ironis melihat potensi hasil laut yang besar, tetapi nelayan berada pada taraf hidup yang rendah bahkan keterbatasan dalam memenuhi kebutuhan sehari-hari[2]. Banyak cabang ilmu komputer yang dapat menyelesaikan masalah secara kompleks. Mereka diantaranya adalah sistem pendukung keputusan [3]-[7], datamining [8]-[11], sistem pakar [12], jaringan saraf tiruan [13]-[16], algoritma genetika [17] dan lain-lain. Cabang ilmu tersebut semuanya masuk kedalam artificial inteligence (AI). Dalam mengatasi hal tersebut, teknik ilmu komputer dapat diterapkan untuk menjawab permasalahan diatas, salah satunya adalah teknik datamining[18] K-Means. Tujuan dari penelitian ini agar hasil pemanfaatan sumber daya ikan oleh nelayan bisa baik, dengan melihat hasil klaster Tempat Pelelangan Ikan (TPI) yang paling sedikit berdasarkan provinsi. Sehingga provinsi yang memiliki TPI klaster rendah dapat menjadi masukan dan perhatian bagi pemerintah setempat untuk pengembangan Tempat Pelelangan Ikan (TPI) agar mengantisipasi perdagangan bebas yang akan dilakukan di indonesia yang akan mempengaruhi nelayan.

\section{TEORITIS}

\subsection{Data Mining}

Data Mining merupakan proses ekstraksi data menjadi informasi yang sebelumnya belum tersampaikan, dengan teknik yang tepat proses data mining akan memberikan hasil yang optimal. Data mining lebih tepat disebut sebagai penambangan pengetahuan dari data, langkah-langkah penting dalam proses penambangan pengetahuan dari data secara umum sebagai berikut :

1. Pembersihan data (data cleaning), yaitu proses menghapus data pengganggu (noise) yang dikatakan tidak konsisten atau tidak diperlukan. 
2. Integrasi data (data integration), yaitu menggabungkan berbagai sumber data.

3. Pemilihan data (data selection), yaitu memilih data yang dipilih sesuai kebutuhan analisis.

4. Transformasi data (data transformation), yaitu proses transformasi data ke dalam format untuk diproses dan siap ditambang.

5. Penggalian data (data mining), yaitu menerapkan metode kecerdasan untuk ekstraksi pola.

6. Evaluasi pola (pattern evaluation), yaitu mengidentifikasi pola-pola yang menarik yang merepresentasikan pengetahuan.

7. Penyajian pola (knowledge presentation), yaitu teknik untuk memvisualisasikan pola pengetahuan ke pengguna[19].

\subsection{Metode K-Means}

K-Means merupakan salah satu metode data clustering non hirarki yang berusaha mempartisi data yang ada ke dalam bentuk satu atau lebih kelompok. Banyak penelitian terdahulu yang penyelesaiannya menggunakan teknik metode k-means [20]. Algoritma K-Means sangat terkenal karena kemudahan dan kemampuannya untuk mengcluster data yang besar dan data outlier dengan sangat cepat [21].

\section{HASIL DAN PEMBAHASAN}

Dalam metode K-means pada Produksi Perikanan Laut Di Tempat Pelelangan Ikan (TPI), diperlukan data mengenai hal tersebut. Sumber data penelitian diperoleh dari data yang dikumpulkan berdasarkan situs https://www.bps.go.id. Data akan diolah dengan melakukan clustering Produksi Perikanan Laut Di Tempat Pelelangan Ikan (TPI) dalam 2 cluster yakni dengan cluster tinggi dan cluster rendah. Dalam menentukan cluster berdasarkan data yang telah tersedia, dibutuhkan sebuah flowchart untuk memudahkan dalam menentukan alur perhitungan sebagai alur untuk menemukan hasil dari penerapan cluster terhadap data yang akan diproses. Berikut adalah flowchart dalam menentukan cluster dengan K-Means.

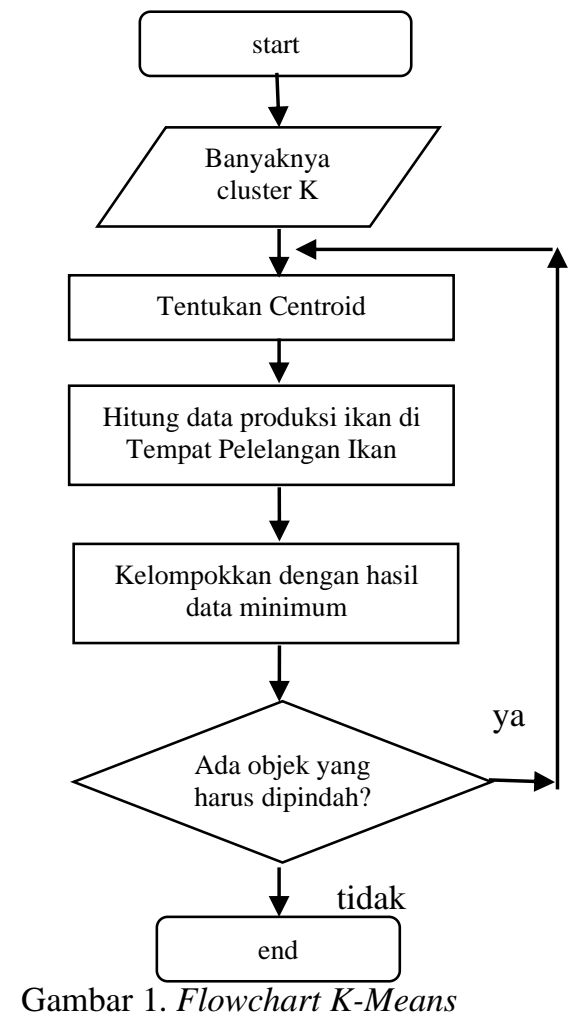

Dalam melakukan clustering, data yang diperoleh akan dihitung terlebih dahulu berdasarkan Produksi Ikan Laut di Tempat Pelelangan Ikan (TPI) pada tahun 2013-2017 berdasarkan provinsi.

Tabel 1. Data Produksi Ikan Laut 2013-2017

\begin{tabular}{lccccc}
\hline \multicolumn{1}{c}{ Provinsi } & $\mathbf{2 0 1 3}$ & $\mathbf{2 0 1 4}$ & $\mathbf{2 0 1 5}$ & $\mathbf{2 0 1 6}$ & $\mathbf{2 0 1 7}$ \\
\hline Aceh & 9435 & 117171 & 45190 & 21479,5 & 43305,88 \\
Sumatera Utara & 7305 & 7221 & 3965,3 & 4571,7 & 15436,76 \\
Sumatera Barat & 1414 & 1775,6 & 1709,7 & 666,9 & 281,9 \\
Bengkulu & 392900 & 3120 & 2615,4 & 2565,4 & 3441,58
\end{tabular}




\begin{tabular}{lccccc} 
Lampung & 2978 & 2816,6 & 4105,9 & 1159,2 & 1533,14 \\
Kepulauan Bangka Belitung & 16970 & 1438,7 & 1242,7 & 2936,6 & 4755,81 \\
DKI Jakarta & 23846 & 26601,1 & 24035,1 & 104956,9 & 44613,42 \\
Jawa Barat & 85996 & 78975,5 & 52361,5 & 46470,2 & 44613,43 \\
Jawa Tengah & 178259 & 193939,1 & 2145005,3 & 221842,8 & 195967,97 \\
DI Yogyakarta & 1397 & 2769,6 & 2339,5 & 1700 & 3088,7 \\
Jawa Timur & 60953 & 93498.90 & 71696.80 & 59520.20 & 156599.68 \\
Banten & 4071 & 7525,5 & 5401,3 & 5758,4 & 6474,66 \\
Bali & 4506 & 11058,3 & 11153,2 & 8664,5 & 8451,25 \\
Nusa Tenggara Barat & 5637 & 5689 & 6122,6 & 3530,5 & 3185,07 \\
Kalimantan Barat & 1020 & 4125,8 & 4159,2 & 3838,1 & 2932,12 \\
Kalimantan Tengah & 6216 & 4612,5 & 12433,4 & 18694,2 & 14336,18 \\
Sulawesi Utara & 814 & 11848,2 & 9595 & 15306,1 & 51908,9 \\
Sulawesi Tengah & 2314 & 3341,3 & 3455,3 & 4149,5 & 3409,3 \\
Sulawesi Selatan & 14568 & 23483,2 & 29684,7 & 20601,5 & 45546,4 \\
Sulawesi Tenggara & 5172 & 4030,9 & 4161,8 & 5920,4 & 6678,31 \\
Gorontalo & 5348 & 4466,7 & 4383,4 & 3188,8 & 3219,02 \\
\hline
\end{tabular}

Sumber : Badan Pusat Statistik, url : https://www.bps.go.id

Data tersebut kemudian diakumulasikan kedalam satu kriteria seperti yang ditujukan pada tabel 2 berikut:

\begin{tabular}{lr} 
Tabel 2. Data akumulasi Produksi Ikan La \\
\hline \multicolumn{1}{c}{ PROVINSI } & \multicolumn{1}{c}{ X } \\
\hline Aceh & 47316,28 \\
Sumatera Utara & 7699,952 \\
Sumatera Barat & 1169,62 \\
Bengkulu & 80928,48 \\
Lampung & 2518,568 \\
Kepulauan Bangka Belitung & 5468,762 \\
DKI Jakarta & 44810,5 \\
Jawa Barat & 61683,33 \\
Jawa Tengah & 587002,8 \\
DI Yogyakarta & 2258,96 \\
Jawa Timur & 60953 \\
Banten & 5846,172 \\
Bali & 8766,65 \\
Nusa Tenggara Barat & 4832,834 \\
Kalimantan Barat & 3215,044 \\
Kalimantan Tengah & 11258,46 \\
Sulawesi Utara & 17894,44 \\
Sulawesi Tengah & 3333,88 \\
Sulawesi Selatan & 26776,76 \\
Sulawesi Tenggara & 5192,682 \\
Gorontalo & 4121,184 \\
\hline
\end{tabular}

\subsection{Centroid Data}

Dalam penerapan algoritma K-means dihasilkan nilai cetroid dari data yang diperolah dengan syarat bahwa pengelompokan yang ingin ditentukan adalah 2, Penetuan cluster dibagi atas dua bagian yakni cluster tingkat distribusi tinggi $(\mathrm{C} 1)$ dan cluster tingkat distribusi rendah $(\mathrm{C} 2)$. Maka nilai centroid juga terdapat 2 titik. Penentuan titik cluster ini dilakukan dengan mengambil nilai terbesar(maksimum) untuk cluster tingkat distribusi tinggi (C1) dan nilai terkecil(minimum) untuk cluster tingkat distribusi rendah (C2). Nilai titik tersebut dapat diketahui pada Tabel 3 berikut:

\begin{tabular}{lc} 
Tabel 3. Centroid data awal \\
\hline Atribut & Nilai \\
C1 & 587002,834 \\
C2 & 1169,62 \\
\hline
\end{tabular}

\subsection{Clustering Data}

Dengan hasil centroid diatas maka data tersebut dibuat menjadi 2 cluster. Proses pengelompokan dengan menentukan jarak terdekat dari setiap data yang diolah. Dari data produksi ikan laut diperoleh pengelompokan pada iterasi 1 untuk 2 cluster tersebut. Cluster tingkat distribusi tinggi (C1) yakni Jawa Tengah, cluster tingkat distribusi rendah (C2) yakni Sumatera Barat. Proses pencarian jarak terdekat, pengelompokan data pada iterasi 1 dan Clustering data dapat digambarkan pada tabel dan gambar berikut: 
Tabel 4. Perhitungan Produksi Ikan Laut

\begin{tabular}{lrrrr}
\hline \multicolumn{1}{c}{ Provinsi } & \multicolumn{1}{c}{ X } & \multicolumn{1}{c}{ C1 } & \multicolumn{1}{c}{ C2 } & Jarak Terdekat \\
\hline Aceh & 47316,28 & & 538516,934 & 538516,934 \\
Sumatera Utara & 7699,952 & 579302,882 & 578133,262 & 578133,262 \\
Sumatera Barat & 1169,62 & 585833,214 & 584663,594 & 584663,594 \\
Bengkulu & 80928,48 & 506074,354 & 504904,734 & 504904,734 \\
Lampung & 2518,568 & 584484,266 & 583314,646 & 583314,646 \\
Kepulauan Bangka Belitung & 5468,762 & 581534,072 & 580364,452 & 580364,452 \\
DKI Jakarta & 44810,5 & 542192,334 & 541022,714 & 541022,714 \\
Jawa Barat & 61683,33 & 525319,504 & 524149,884 & 524149,884 \\
Jawa Tengah & 587002,8 & 0,034 & 1169,586 & 0,034 \\
DI Yogyakarta & 2258,96 & 584743,874 & 583574,254 & 583574,254 \\
Jawa Timur & 60953 & 526049,834 & 524880,214 & 524880,214 \\
Banten & 5846,172 & 581156,662 & 579987,042 & 579987,042 \\
Bali & 8766,65 & 578236,184 & 577066,564 & 577066,564 \\
Nusa Tenggara Barat & 4832,834 & 582170 & 581000,38 & 581000,38 \\
Kalimantan Barat & 3215,044 & 583787,79 & 582618,17 & 582618,17 \\
Kalimantan Tengah & 11258,46 & 575744,374 & 574574,754 & 574574,754 \\
Sulawesi Utara & 17894,44 & 569108,394 & 567938,774 & 567938,774 \\
Sulawesi Tengah & 3333,88 & 583668,954 & 582499,334 & 582499,334 \\
Sulawesi Selatan & 26776,76 & 560226,074 & 559056,454 & 559056,454 \\
Sulawesi Tenggara & 5192,682 & 581810,152 & 580640,532 & 580640,532 \\
Gorontalo & 4121,184 & 582881,65 & 581712,03 & 581712,03 \\
\hline
\end{tabular}

Tabel 5. Pengelompokan Data Iterasi 1

\begin{tabular}{|c|c|c|c|}
\hline No & Provinsi & C1 & $\mathrm{C2}$ \\
\hline 1 & Aceh & & 1 \\
\hline 2 & Sumatera Utara & & 1 \\
\hline 3 & Sumatera Barat & & 1 \\
\hline 4 & Bengkulu & & 1 \\
\hline 5 & Lampung & & 1 \\
\hline 6 & Kepulauan Bangka Belitung & & 1 \\
\hline 7 & DKI Jakarta & & 1 \\
\hline 8 & Jawa Barat & & 1 \\
\hline 9 & Jawa Tengah & 1 & \\
\hline 10 & DI Yogyakarta & & 1 \\
\hline 11 & Jawa Timur & & 1 \\
\hline 12 & Banten & & 1 \\
\hline 13 & Bali & & 1 \\
\hline 14 & Nusa Tenggara Barat & & 1 \\
\hline 15 & Kalimantan Barat & & 1 \\
\hline 16 & Kalimantan Tengah & & 1 \\
\hline 17 & Sulawesi Utara & & 1 \\
\hline 18 & Sulawesi Tengah & & 1 \\
\hline 19 & Sulawesi Selatan & & 1 \\
\hline 20 & Sulawesi Tenggara & & 1 \\
\hline 21 & Gorontalo & & 1 \\
\hline
\end{tabular}

Proses K-Means akan terus berlanjut sampai pengelompokan data sama dengan pengelompokan data pada iterasi sebelumnya. Proses iterasi ini berhenti sampai dengan iterasi kelima, berikut adalah hasil perhitungan iterasi ke 5 dapat diketahui pada Tabel 6 berikut :

Tabel 6. Centroid data iterasi 5

\begin{tabular}{lc} 
Atribut & Nilai \\
C1 & 587002,8 \\
C2 & 20302,28 \\
\hline
\end{tabular}

Setelah mendapatkan nilai centroid, proses sama dilakukan dengan mencari jarak terdekat. Pengelompokan data pada iterasi 5 dan pengelompokan data dapat ditunjukan pada tabel 7 berikut:

Tabel 7. Produksi Ikan Laut cluster iterasi 5

\begin{tabular}{lrrr}
\hline \multicolumn{1}{c}{ Provinsi } & C1 & \multicolumn{1}{c}{ C2 } & Jarak Terdekat \\
\hline Aceh & 539686,6 & 27014 & 27014 \\
Sumatera Utara & 579302,9 & 12602,33 & 12602,33 \\
Sumatera Barat & 585833,2 & 19132,66 & 19132,66 \\
Bengkulu & 506074,4 & 60626,2 & 60626,2
\end{tabular}




\begin{tabular}{lrrr} 
Lampung & 584484,3 & 17783,71 & 17783,71 \\
Kepulauan Bangka Belitung & 581534,1 & 14833,52 & 14833,52 \\
DKI Jakarta & 542192,3 & 24508,23 & 24508,23 \\
Jawa Barat & 525319,5 & 41381,05 & 41381,05 \\
Jawa Tengah & 0 & 566700,6 & 0 \\
DI Yogyakarta & 584743,9 & 18043,32 & 18043,32 \\
Jawa Timur & 526049,8 & 40650,72 & 40650,72 \\
Banten & 581156,7 & 14456,11 & 14456,11 \\
Bali & 578236,2 & 11535,63 & 11535,63 \\
Nusa Tenggara Barat & 582170 & 15469,44 & 15469,44 \\
Kalimantan Barat & 583787,8 & 17087,23 & 17087,23 \\
Kalimantan Tengah & 575744,4 & 9043,821 & 9043,821 \\
Sulawesi Utara & 569108,4 & 2407,837 & 2407,837 \\
Sulawesi Tengah & 583669 & 16968,4 & 16968,4 \\
Sulawesi Selatan & 560226,1 & 6474,483 & 6474,483 \\
Sulawesi Tenggara & 581810,2 & 15109,6 & 15109,6 \\
Gorontalo & 582881,7 & 16181,09 & 16181,09 \\
\hline
\end{tabular}

Tabel 8. Pengelompokan data iterasi 5

\begin{tabular}{clcc}
\hline No & \multicolumn{1}{c}{ Provinsi } & C1 & C2 \\
\hline 1 & Aceh & 1 \\
2 & Sumatera Utara & 1 \\
3 & Sumatera Barat & \\
4 & Bengkulu & 1 \\
5 & Lampung & 1 \\
6 & Kepulauan Bangka Belitung & & 1 \\
7 & DKI Jakarta & 1 \\
8 & Jawa Barat & 1 \\
9 & Jawa Tengah & 1 & \\
10 & DI Yogyakarta & 1 \\
11 & Jawa Timur & 1 \\
12 & Banten & 1 \\
13 & Bali & 1 \\
14 & Nusa Tenggara Barat & 1 \\
15 & Kalimantan Barat & 1 \\
16 & Kalimantan Tengah & 1 \\
17 & Sulawesi Utara & 1 \\
18 & Sulawesi Tengah & 1 \\
19 & Sulawesi Selatan & 1 \\
20 & Sulawesi Tenggara & 1 \\
21 & Gorontalo & 1 \\
\hline
\end{tabular}

Setelah diakumulasikan maka akan didapatkan nilai dari produksi ikan laut di Tempat Pelelangan Ikan (TPI). Kemudian data tersebut akan masuk ke tahapan clustering dengan menerapkan algoritma K-Means menggunakan RapidMinner untuk meng-cluster data menjadi dua cluster.

1. Text view : merupakan sheet untuk menampilkan database yang telah diolah secara keseluruhan lengkap dengan clusternya. Tampilan dari cluster model (clustering) dapat lihat pada gambar berikut:

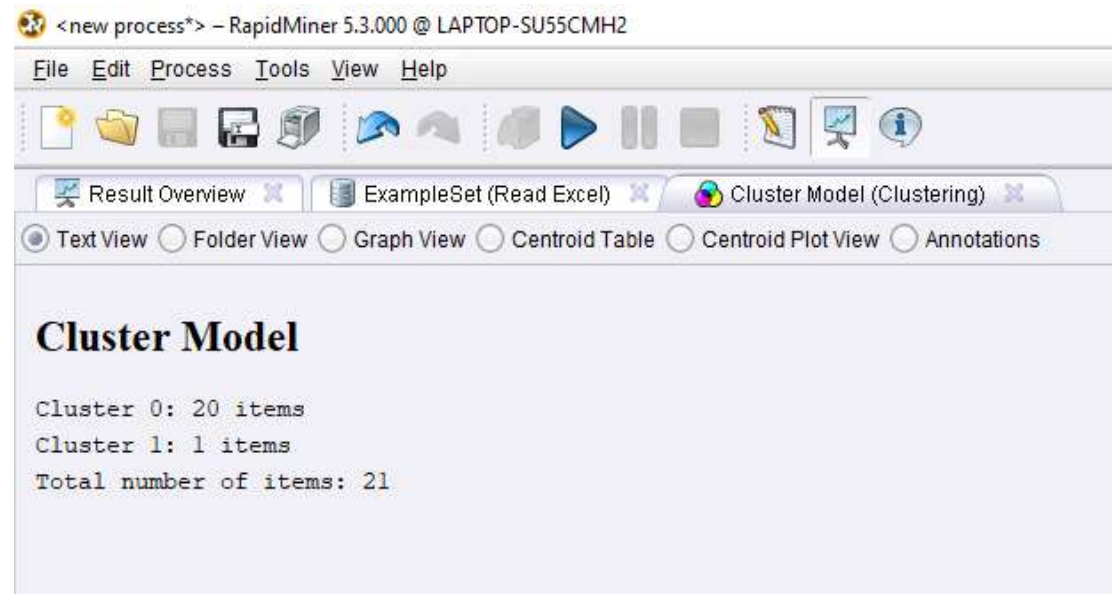

Gambar 1. Text View 
2. Folder view : merupakan sheet untuk menampilkan database yang telah diolah secara keseluruhan lengkap dengan clusternya. Tampilan folder view dapat dilihat pada gambar berikut:

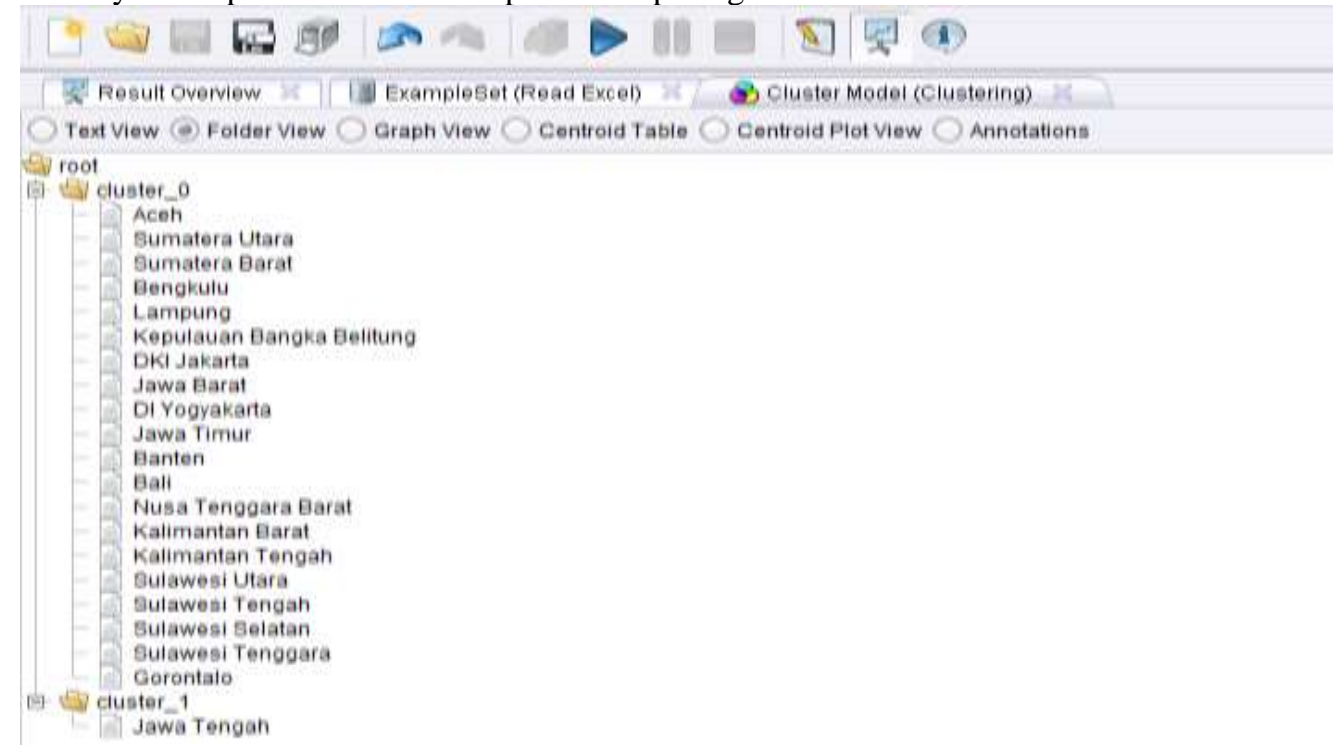

Gambar 2. Folder View

\section{KESIMPULAN}

Berdasarkan penelitian diatas dapat disimpulkan K-Means Clustering dan data dibantu dengan menggunakan software RapidMiner dalam melalukan pemanfaat sumber daya ikan berdasarkan Provinsi oleh nelayan bisa lebih baik lagi. Hasil penelitian dari 21 Provinsi di Indonesia didapat clustring tingkat tinggi(C1) yaitu Jawa Tengah, sedangkan clustring tingkat rendah(C2) adalah provinsi Aceh, Sumatera Utara, Sumatera Barat, Bengkulu, Lampung, Kepulauan Bangka Belitung, DKI Jakarta, Jawa Barat, DI Yogyakarta, Jawa Timur, Banten, Bali, Nusa Tenggara Barat, Kalimantan Barat, Kalimantan Tengah, Sulawesi Utara, Sulawesi Tengah, Sulawesi Selatan, Sulawesi Tenggara dan Gorontalo.

\section{REFERENCES}

[1] K. Pelabuhan, P. Muara, and K. Kabupaten, "KAJIAN PENGEMBANGAN TEMPAT PELELANGAN IKAN (TPI) DI SENTRA KAWASAN PELABUHAN PERIKANAN MUARA KINTAP KABUPATEN TANAH LAUT PROVINSI KALIMANTAN SELATAN,” vol. 12, no. 2, pp. 69-77, 2016.

[2] G. Maskie and Y. P. Pratama, "KAJIAN OPERASIONAL TEMPAT PELELANGAN IKAN (TPI) DAN KESEJAHTERAAN MASYARAKAT NELAYAN ( Studi Kasus Desa Watukarung Kecamatan Pringkuku Kabupaten Pacitan )," vol. 14, no. 2, p. 20, 2014.

[3] S. M. Dewi and A. P. Windarto, "Analisis Metode Electre Pada Pemilihan Usaha Kecil Home Industry Yang Tepat Bagi Mahasiswa," Sist. J. Sist. Inf., vol. 8, no. 3, pp. 377-385, 2019.

[4] D. R. S. P, A. A. Muin, and M. Amin, "PEMILIHAN FACIAL WASH UNTUK KULIT WAJAH BERMINYAK DENGAN METODE PROMETHEE II," CESS (Journal Comput. Eng. Syst. Sci., vol. 4, no. 2, pp. 222-229, 2019.

[5] C. Astria, A. P. Windarto, and Z. Musiafa, "PEMILIHAN PRODUK SAMPO SESUAI JENIS KULIT KEPALA DENGAN METODE PROMETHEE II,” CESS (Journal Comput. Eng. Syst. Sci., vol. 4, no. 2, pp. 178-185, 2019.

[6] D. N. Batubara, A. P. Windarto, and M. R. Raharjo, "PENERAPAN PROMETHEE II PADA PEMILIHAN PRODUK CONDITIONER SEBAGAI UPAYA PENINGKATAN MINAT BELI KONSUMEN," CESS (Journal Comput. Eng. Syst. Sci., vol. 4, no. 2, pp. 191-197, 2019.

[7] D. N. Batubara, D. R. S. P, and A. P. Windarto, "Penerapan Metode PROMETHEE II Pada Pemilihan Situs Travel Berdasarkan Konsumen,” J. SISFOKOM, vol. 8, no. 1, pp. 46-52, 2019.

[8] A. P. Windarto, "Penerapan Datamining Pada Ekspor Buah-Buahan Menurut Negara Tujuan Menggunakan K-Means Clustering Method," Techno.Com, vol. 16, no. 4, pp. 348-357, 2017.

[9] M. G. Sadewo et al., "PENERAPAN ALGORITMA CLUSTERING DALAM MENGELOMPOKKAN BANYAKNYA DESA / KELURAHAN MENURUT UPAYA ANTISIPASI / MITIGASI BENCANA ALAM MENURUT PROVINSI DENGAN K-MEANS,” vol. 2, pp. 311-319, 2018.

[10] H. Siahaan, H. Mawengkang, S. Efendi, A. Wanto, and A. P. Windarto, "Application of Classification Method C4 . 5 on Selection of Exemplary Teachers," in IOP Conference Series, 2018, pp. 1-6.

[11] Sudirman, A. P. Windarto, and A. Wanto, "Data mining tools | rapidminer: K-means method on clustering of rice crops by province as efforts to stabilize food crops in Indonesia," IOP Conf. Ser. Mater. Sci. Eng., vol. 420, p. 12089, 2018.

[12] S. Azhar, H. Latipa, S. Leni, and N. Zulita, "Sistem Pakar Penyakit Ginjal Pada Manusia Menggunakan Metode Forward Chaining," J. Media Infotama, vol. 10, no. 1, pp. 16-26, 2014. 
[13] T. Budiharjo, Soemartono, T., Windarto, A.P., Herawan, "Predicting tuition fee payment problem using backpropagation neural network model," Int. J. Adv. Sci. Technol., 2018.

[14] T. Budiharjo, Soemartono, T., Windarto, A.P., Herawan, "Predicting school participation in indonesia using back-propagation algorithm model," Int. J. Control Autom., 2018.

[15] A. P. Windarto, M. R. Lubis, and Solikhun, "MODEL ARSITEKTUR NEURAL NETWORK DENGAN BACKPROPOGATION PADA PREDIKSI TOTAL LABA RUGI KOMPREHENSIF BANK UMUM KONVENSIONAL," Kumpul. J. Ilmu Komput., vol. 5, no. 2, pp. 147-158, 2018.

[16] A. P. Windarto, M. R. Lubis, and Solikhun, "IMPLEMENTASI JST PADA PREDIKSI TOTAL LABA RUGI KOMPREHENSIF BANK UMUM KONVENSIONAL DENGAN BACKPROPAGATION," J. Teknol. Inf. dan Ilmu Komput., vol. 5, no. 4, pp. 411-418, 2018.

[17] Sumijan, A. P. Windarto, A. Muhammad, and Budiharjo, "Implementation of Neural Networks in Predicting the Understanding Level of Students Subject," Int. J. Softw. Eng. Its Appl., vol. 10, no. 10, pp. 189-204, 2016.

[18] D. N. Batubara, A. P. Windarto, D. Hartama, and H. Satria, “Analisis Metode K-MEANS Pada Pengelompokan Keberadaan Area Resapan Air Menurut Provinsi," no. x, pp. 345-349, 2019.

[19] G. Abdillah et al., "PENERAPAN DATA MINING PEMAKAIAN AIR PELANGGAN UNTUK MENENTUKAN KLASIFIKASI POTENSI PEMAKAIAN AIR PELANGGAN BARU DI PDAM TIRTA RAHARJA MENGGUNAKAN ALGORITMA K-MEANS,” vol. 2016, no. Sentika, pp. 18-19, 2016.

[20] C. Astria, A. P. Windarto, A. Wanto, and E. Irawan, "Metode K-Means Pada Pengelompokan Wilayah Pendistribusian Listrik," pp. 306-312, 2019.

[21] B. M. Metisen and H. L. Sari, "Analisis Clustering Menggunakan Metode K-Means dalam Pengelompokkan Penjualan Produk pada Swalayan Fadhila," J. Media Infotama, vol. 11, no. 2, pp. 110-118, 2015. 